\title{
Critical Success Factors Plays a Vital Role in ERP Implementation in Developing Countries: An Exploratory Study in Pakistan
}

\author{
Naeem Ahmed \\ PhD Scholar, Department of \\ Computer Science \\ Federal Urdu University of Arts and \\ Technology \\ Karachi, Pakistan
}

\author{
Dr. A. A. Shaikh \\ Assistant Professor, Department of \\ Computer Science \\ Institute of Business Administration \\ (IBA) \\ Karachi, Pakistan
}

\author{
Dr. Muhammad Sarim \\ Assistant Professor, Department of \\ Computer Science \\ Federal Urdu University of Arts and \\ Technology \\ Karachi, Pakistan
}

\begin{abstract}
The capabilities of an Enterprise Resource Planning (ERP) system to integrate all the business functions needed in a single system with a shared database efficiently and effectively has persuaded organizations to adopt them. In enterprise environment, successful ERP implementation has played a vital role for organizational efficiency. In this respect critical success factors (CSFs) have been identified essential for the successful ERP implementation. The purpose of this paper is to identify and analyze CSFs impacting ERP implementation success in Pakistani Small and Medium Sized Enterprises (SMEs). This paper will help Pakistani SME's on how to obtain better results from ERP implementation focusing on CSFs relevant to them.
\end{abstract}

Keywords-Information System (IS); Enterprise Resource Planning (ERP) System; ERP implementation; CSFs; Pakistani Small and Medium Sized Enterprises (SMEs); Statistical Package for Social Sciences (SPSS)

\section{INTRODUCTION}

The organizations in the current IT age need to use information systems effectively which require an understanding of the organization, management, and information technology that form the information systems [1].

Since the mid-90s, Information System (IS) researchers have concentrated their research efforts on the development and testing of models that help investigate aspects of IS in different environments. As a result, a series of models to study the use of ERP Systems, their effect on end-user and other related topics, including system success and their effect on business in the organizations [2].

Enterprise Resources Planning (ERP) is an information system designed for the integration and optimization of processes, as well as transactions in an organization. ERP is universally accepted by organizations throughout the world as a professional solution to achieve desired business goals [3].

ERP projects usually require the investment of a large amount of capital, time, and other business resources. As process orientation is proving to have positive effects on organizational efficiency and performance [4], many organizations are moving from a functional to a process-based
IT infrastructure, with ERP systems comprising the central component of such an infrastructure. However, ERP systems provide standardized processes/features to support work procedures or user tasks, which are, in most cases, not perfectly matched. User requirements are also very likely to change after the initial implementation period of the ERP system, for reasons both internal - business process improvement and redesign projects, and external - competitors' moves or changing government regulations. Managing changes in user requirements, and at the same time, maintaining users' satisfaction and benefits, becomes a critical organizational issue for the success of their costly ERP projects postimplementation [5].

For the development of the organization when investing in IT, the project must be calculated according to its capacity, timely delivery, cost, risk avoidance and quality keeping [6].

In the 1980s the word Critical Success Factors (CSF) was introduced under research work, in order to determine why some organizations have been more successful than others. The term Critical Success Factors (CSF) is defined as "those things that must be done if a company is to be successful" and it is quantifiable and controllable [7].

Since then the large organizations targeted by the ERP markets have become saturated, ERP system vendors have now shifted to Small and Medium-sized enterprises (SMEs) market. Resultantly a largely fragmented ERP market has emerged into all the industries of all sizes [8].

\section{RESEARCH OBJECTIVES}

This study focuses on determining which factors are critical to implementing ERP successfully in SMEs in Pakistan.

The objectives of this paper are to

- identify the CSFs for ERP Implementation;

- study the impact of CSFs on ERP success in Pakistani SMEs;

- recognizing the impact on organizational and technological aspects; and 
- define a framework for successful ERP implementation in Pakistani SMEs.

\section{LITERATURE REVIEW}

Legacy systems constituted the early enterprise systems within organizations. These systems usually resolved specific departmental needs but did not have the capacity to integrate them. Therefore, it was usual to collect and process the same information several times in different places, creating a serious challenge when policy makers tried to access the right piece of real-time information. This platform generated serious asymmetries between different functional groups within the same organization [9]. To overcome these issues, new systems came into being, known as "Enterprise Resource Planning" (ERP), a term coined by Gartner Group [10].

\section{A. ERP Implementation}

Implementation of information systems (IS) in general is quite difficult. It is dependent upon organization size, scope and organization process complexity. According To ERP report 2016 From Panorama Consulting Group LLC, [11], results shows that ERP implementation success rate is $57 \%$ and only 7\% ERP implementation fails to get desired results these results shows that ERP success rate is on the higher side.

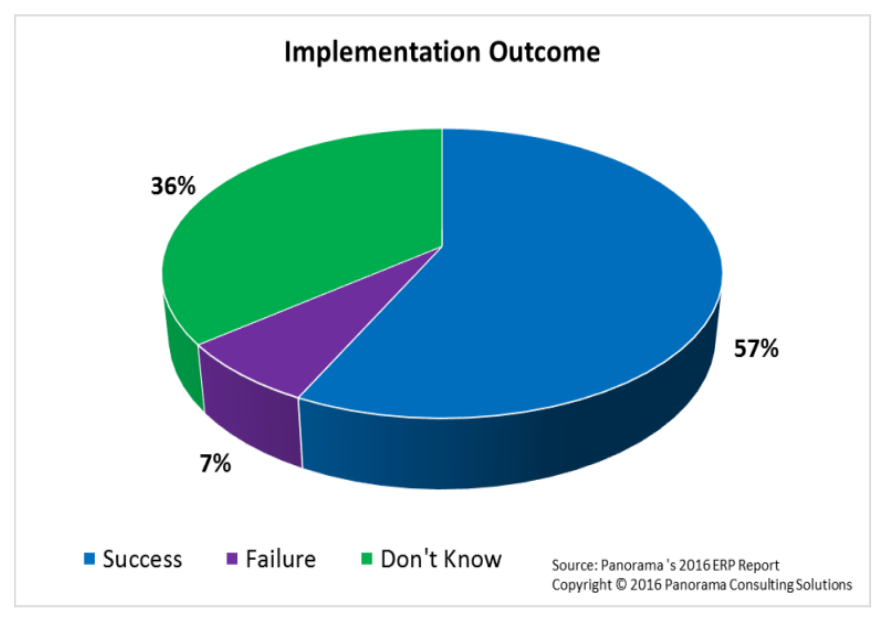

Fig. 1. ERP implementation outcome.

ERP implementation is very important - a survey in 2013 shows that $54 \%$ of ERP projects were reported to be cost overruns, $72 \%$ were late and $66 \%$ of companies the implementation of ERP software initiatives received less than $50 \%$ of the expected measurable benefits [12] as shown in Fig. 1.

\section{B. ERP Implementation in Large Enterprises}

Large Enterprises have streamline processes, proper IT Infrastructure and qualified personnel in their organizations. Large-size organizations have sufficient funds and a proper structured predefined flow of processes. That is why ERP implementation in large enterprises is prone to succeed. Large Enterprises (LE's) invest huge money in ERP Implementation to get desired results quickly as possible and they achieve their goals within targets (budget, time, accuracy) [13].

\section{ERP Implementation in Small and Medium Size Enterprise (SMEs)}

SMEs are increasingly in focus because of their huge potential for growth and vary in size, age, sector and knowledge base with innovative capacity [14].

They constitute the vast majority of industrial units and services worldwide and are a source of employment. High-tech SMEs embraced, high quality standards and competitiveness and have continued expanding faster than the rest of the industrial economy [14].

The SME sector in Pakistan contributes to nearly $30 \%$ of GDP in Pakistan and, contains about 12 million units and employing nearly 30 million peoples. The sector adapted and restructured to face competition from global players to respond quickly [15].

In the industrial development of a country the importance of the SME sector cannot be overemphasized. SMEs constitute nearly $90 \%$ of all businesses in Pakistan; employ $80 \%$ of the non-agricultural labor; and their share in the annual GDP is about $40 \%$ [16]. However, unlike large enterprises in the formal sector, small and medium enterprises are limited by financial and other resources.

IT is recognized as a viable, competitive actor facilitating increased productivity, better profitability, and value for customers [17]. The role of Information Technology (IT) in competitiveness has been mainly focused on large organizations. However, on the world market today, and in the era of e-commerce, small and medium size enterprises (SMEs) can use IT to improve their competitive positions with their larger counterparts [18]. Quigley et al. [19] showed that small businesses are using the Internet more than their counterparts. To take full advantage of IT and compete in the global business environment, business leaders must recognize the strategic value of IT and to exploit it.

Pakistan is a developing country, which is why many organizations have not implemented proper IT infrastructure. In a survey conducted by Irfan et al. [20], only 16\% SMEs were using computers.

Although ERP systems were first designed to run in large companies, SMEs were increasingly motivated to introduce ERP [21]. SMEs attempted to improve their organizational performance by implementing ERP in their organizations but did not achieve desired results. Many small businesses still use outdated applications that do not support the emerging business practices [22].

Saini et al. [23] concludes that SMEs have the same needs as large enterprises, but face different challenges because of their limited resources and financial capabilities. Marsh [24] confirmed that SMEs do not have sufficient resources or are not willing to devote a significant part of their resources to a complex ERP implementation process. A better understanding of the ERP implementation in SMEs is necessary to ensure to get high results from ERP. 


\section{ERP Implementation Success}

In fact, implementing ERP systems is now a common practice in the world. Although ERP is now a very common phenomena, but the ratio of unsuccessful implementation of ERP is still high [25].

The literature review shows that successful implementation of ERP and failure is not conclusive. While some analysts point positive impacts and results of the ERP application, others report ERP failures. One of the reasons for these different points of views lies in the multidimensionality of the concept of success and difficulty of developing a single success and failure measurement [26].

If these goals are set before ERP implementation begins, the benefits or targets will be evaluated based on whether these goals are achieved or not. If these goals are not set before ERP implementation begins, the ERP will not be able help to get desired results, as targets will change. ERP success and failure depends upon what you want to achieve from ERP and whether it is achievable or not.

\section{E. Critical Success Factors (CSFs)}

The concept of 'success factors' was first introduced by Daniel (1961) in his seminar HBR article "Crisis of management information". He differentiates between three types of useful data for companies: environmental, competitive and internal; and argues that the enterprise information system (IS) should be discriminatory and selective in reporting internal data. An IS should focus on the factors of success, which according to him usually are three to six for most of the companies in an industry and are defined as those key jobs which must be done exceedingly well for a company to be successful [26].

One of the main research issues in today's ERP systems is to study the ERP implementation success. Critical success factors (CSF) are those factors which are essential to achieve organizational desired goals from ERP.

Many studies have sought to identify factors that positively affect the success of ERP installations. Relevant studies include Li, Hsing-Jung et al. [27], Kulkarni et al. [28], Baykasoğlu et al. [29], Nagpal et al. [30], Saygili et al. [31], Lloyd Miller et al. [32], Kalinga et al. [33], among others.

The success of all ERP projects depends directly on the success of the CSFs. Some other studies related to CSFs on projects have mainly explored the four issues.

- What are the critical factors that influence the success of ERP Implementation at SMEs?

- Which critical factors should get high priority in judging the success of ERP implementation at SMEs?

- What factors are there to illustrate the success of ERP implementation?

- What factors led to successful ERP in a coherent manner?

\section{RESEARCH METHODOLOGY}

The main purpose of this research was to determine the factors that contribute to the success and failure of ERP implementation in Pakistani SMEs. In this research, qualitative analyses with quantitative ratings have been used to create the summary. The research is focused on "Pakistani SMEs and Pakistani ERP Consultants (Specific to Pakistan)".

In this research, ERP Implementation success is considered the dependent variable and organizational factors, human resources factors, project management factors, ERP factors are taken as independent variables. Data is collected through a customized questionnaire and then analyzed.

A questionnaire was developed for this study. The draft of the questionnaire items was extracted from various previous research studies and adapted for this research.

A two-part survey was developed to collect data for analysis and hypothesis testing. The questionnaire was developed in two phases. This method is a popular method to design proper well defined questionnaire used in various research [34], [35].

Phase 1: A pilot questionnaire was sent out. The draft of the questionnaire was developed was from previous research studies and customized for our research. This pilot questionnaire was further examined by 10 ERP Implementation experts, who had experience in the use of enterprise information systems such as SAP, Oracle Businesses Suite, MS Dynamics, or any home-grown ERP system.

Phase 2: The questionnaire was revised accordingly and used it in a pilot test-II with 15 Pakistani ERP consultants. Therefore, the initial survey instrument was revised extensively. Research methodology framework described in Fig. 2.

The survey, respondents were requested to provide answers on a 5-point Likert scale.

- 5 - Strongly Agree

- 4- Agree

- 3 - Neutral

- 2 - Disagree

- 1 - Strongly Disagree.

In the case of respondents from leading organizations, the research questionnaire was intended for those individuals who played a leading role in the ERP implementation (i.e. ERP Manager, ERP Project Managers, Head of IT, etc.). They had insight into their projects and were able to answer the survey questions and evaluate the measures included in the questionnaires.

During the research 400 respondents were contacted and 60 responses were obtained (response rate is 15\%) from companies representing various industries in Pakistan. 


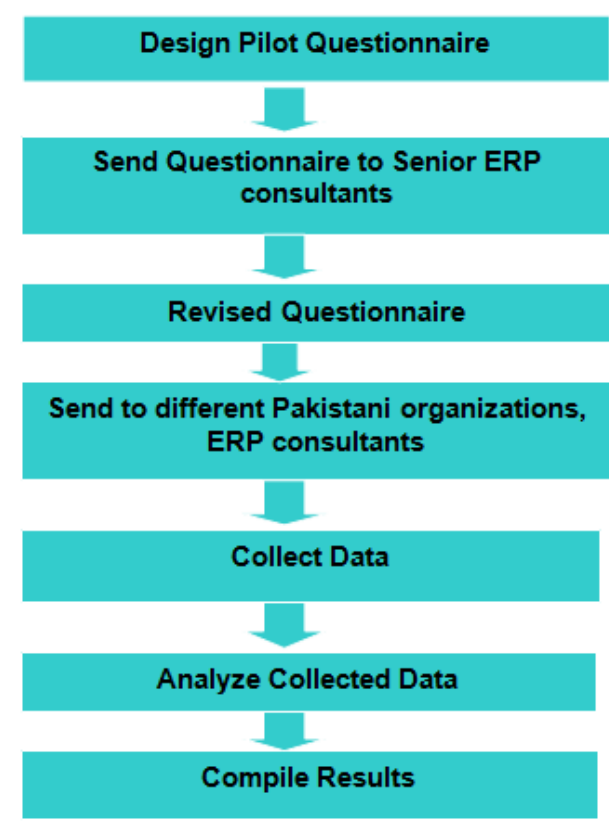

Fig. 2. Research methodology framework.

\section{RESULTS AND DISCUSSION}

In order to illustrate the respondents' point of view on regarding the importance of proposed factors, an average was calculated for each factor. These calculations have been made from all experts opinions.

CSFs for successful ERP implementation in Pakistani SMEs have been identified through extensive literature review and further examining by ERP Implementation experts, then determining whether it was complete and clear. Most of the earlier research has not specifically focused on SME sector and the research has been broad based. It has been assumed that CSFs identified from ERP implementation and other industries will be applicable for ERP implementation in SMEs. In this study, a total of 38 CSFs have been identified which are grouped in 4 Categories (describe in Fig. 3). The same is presented in Appendix I.

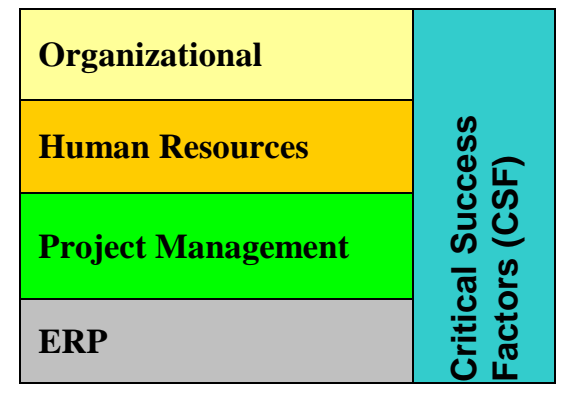

Fig. 3. High level research conceptual model.

SPSS (Statistical Package for Social Sciences) was used as data analysis software Package. SPSS further refined the results and output data in different ways (i.e. validity test, reliability test, factor analysis etc.).

\section{A. Reliability Test}

Reliability test for the instruments were conducted from the survey data. The Cronbach coefficient $(\alpha)$ was calculated to test the reliability and internal consistency of the responses. Cronbach's alpha reliability coefficient normally ranges between 0 and 1 . The closer the coefficient is to 1 , the greater is the internal consistency of the items (variables) in the scale.

The value of $\alpha$ in this study was found to be $\mathbf{0 . 9 4 9}$ (Cronbach's alpha reliability coefficient normally ranges between 0 and 1) which is considered highly acceptable. After conducting reliability test, the data was analyzed to obtain the final results.

\section{B. Validity Test}

Validity is a measure of the degree of validity or validity of a research instrument. An instrument is said to be valid if it can measure what is to be measured or desired. An instrument is said to be valid if data for the studied variables can be revealed.

For the group of 60 respondents from Pakistani SMEs validity was found to be $\mathbf{0 . 9 7 4 7}$. The validity was found by using Guilford's formula i.e. by applying the square root of the reliability.

\section{Demographic Analysis}

Demographic analysis is shown in Fig. 4 and respondent industry type results are present in Table 1 and Fig. 5.

Respondents' qualification analysis is shown in Fig. 6.

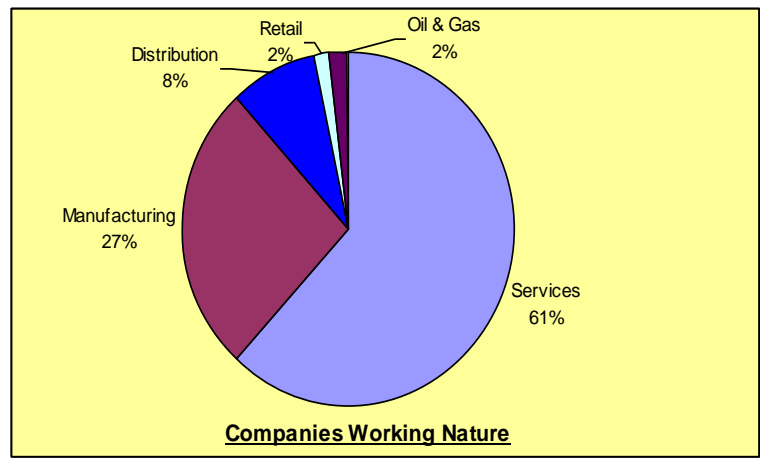

Fig. 4. Companies working nature.

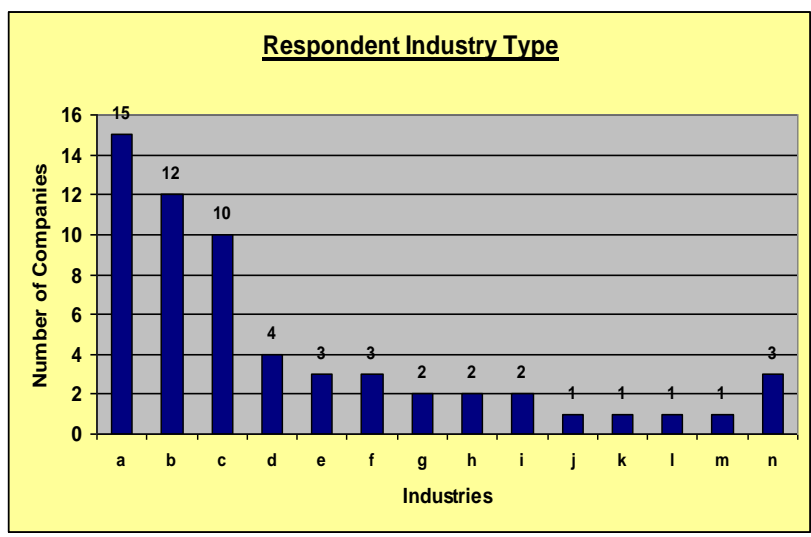

Fig. 5. Respondent industry type. 
TABLE I. RESPONDENT INDUSTRY TYPE

\begin{tabular}{|l|l|l|}
\hline Id & Industries & $\begin{array}{l}\text { Number of } \\
\text { Companies }\end{array}$ \\
\hline $\mathrm{a}$ & Computer Service & $\mathbf{1 5}$ \\
\hline $\mathrm{b}$ & Pharmaceutical & $\mathbf{1 2}$ \\
\hline $\mathrm{c}$ & Healthcare & $\mathbf{1 0}$ \\
\hline $\mathrm{d}$ & Aviation & $\mathbf{4}$ \\
\hline $\mathrm{e}$ & Telecommunication & $\mathbf{3}$ \\
\hline $\mathrm{f}$ & ERP Consultant Firm & $\mathbf{3}$ \\
\hline $\mathrm{g}$ & Bank & $\mathbf{2}$ \\
\hline $\mathrm{h}$ & NGO & $\mathbf{2}$ \\
\hline $\mathrm{i}$ & Utilities & $\mathbf{2}$ \\
\hline $\mathrm{j}$ & Electronic and Electrical & $\mathbf{1}$ \\
\hline $\mathrm{k}$ & Energy Services & $\mathbf{1}$ \\
\hline $\mathrm{l}$ & Insurance, Life and Health & $\mathbf{1}$ \\
\hline $\mathrm{m}$ & Oil \& Gas & $\mathbf{1}$ \\
\hline $\mathrm{n}$ & Others & $\mathbf{3}$ \\
\hline
\end{tabular}

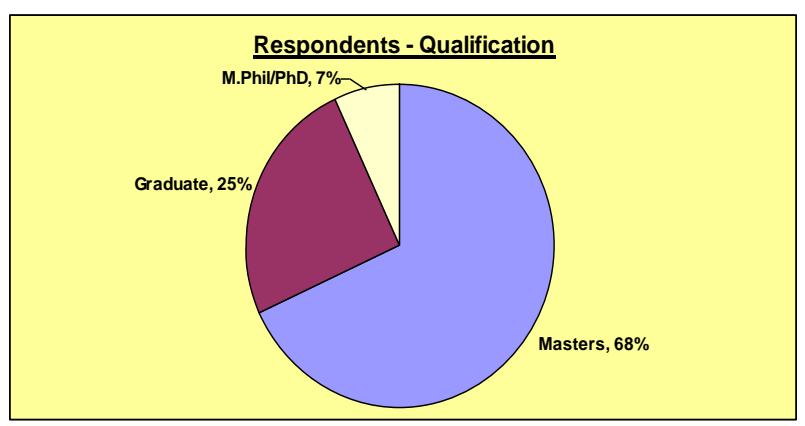

Fig. 6. Respondents - qualification.

\section{Descritptive Analysis}

Table 2 presents basic statistics including mean, standard deviation, mode and variance. The values were well understood in the desirable levels and the analysis of the principle components had to be used to extract the main factors. The values were well within desirable levels and analysis needs to extract the main factors.

Where,

$\mathbf{N}$ : This is the number of valid observations for the variable.

Mean: This is the arithmetic mean across the observations. It is the most widely used measure of central tendency. It is commonly called the average. The mean is sensitive to extremely large or small values.

Variance: The variance is a measure of variability. It is the sum of the squared distances of data value from the mean divided by the variance divisor. The Corrected SS is the sum of squared distances of data value from the mean. Therefore, the variance is the corrected SS divided by $\mathrm{N}-1$.

Standard Deviation: Standard deviation is the square root of the variance. It measures the spread of a set of observations.
The larger the standard deviation is, the more spread out the observations are.

Skewness and Kurtosis are used to validate the data for normality [36]. Table 3 presents including min, max, Skewness and Kurtosis.

Skewness: Skewness measures the degree and direction of asymmetry. A symmetric distribution such as a normal distribution has a Skewness of 0. A positive Skewness value indicates positive (right) skew; a negative value indicates negative (left) skew. The higher the absolute value, the greater the skew is.

Kurtosis: Kurtosis is a measure of tail extremity reflecting either the presence of outliers in a distribution or a distribution's propensity for producing outliers, a positive kurtosis value indicates positive kurtosis; a negative one indicates negative kurtosis. The higher the absolute value, the greater the kurtosis is (shown in Table 3).

\section{TABLE II. DESCRIPTIVE STATISTICS}

\begin{tabular}{|l|l|l|l|l|l|l|l|}
\hline CSF \# & N & Mean & $\begin{array}{l}\text { Std. } \\
\text { Error of } \\
\text { Mean }\end{array}$ & Med & Mod & $\begin{array}{l}\text { Std. } \\
\text { Dev }\end{array}$ & Var \\
\hline C1 & 60 & 4.8 & 0.1 & 5 & 5 & 0.459 & 0.210 \\
\hline C2 & 60 & 4.5 & 0.1 & 5 & 5 & 0.671 & 0.451 \\
\hline C3 & 60 & 4.3 & 0.1 & 4 & 5 & 0.767 & 0.588 \\
\hline C4 & 60 & 4.3 & 0.1 & 4 & 5 & 0.793 & 0.629 \\
\hline C5 & 60 & 4.2 & 0.1 & 4 & 4 & 0.713 & 0.509 \\
\hline C6 & 60 & 4.4 & 0.1 & 4.5 & 5 & 0.726 & 0.528 \\
\hline C7 & 60 & 4.3 & 0.1 & 4 & 5 & 0.715 & 0.511 \\
\hline C8 & 60 & 4.3 & 0.1 & 4 & 5 & 0.719 & 0.517 \\
\hline C9 & 60 & 4.2 & 0.1 & 4 & 4 & 0.694 & 0.481 \\
\hline C10 & 60 & 4.6 & 0.1 & 5 & 5 & 0.579 & 0.336 \\
\hline C11 & 60 & 4.6 & 0.1 & 5 & 5 & 0.560 & 0.313 \\
\hline C12 & 60 & 4.5 & 0.1 & 5 & 5 & 0.646 & 0.418 \\
\hline C13 & 60 & 4.5 & 0.1 & 5 & 5 & 0.695 & 0.484 \\
\hline C14 & 60 & 4.5 & 0.1 & 5 & 5 & 0.695 & 0.483 \\
\hline C15 & 60 & 4.3 & 0.1 & 4 & 4 & 0.637 & 0.406 \\
\hline C16 & 60 & 4.5 & 0.1 & 5 & 5 & 0.619 & 0.383 \\
\hline C17 & 60 & 4.5 & 0.1 & 5 & 5 & 0.593 & 0.351 \\
\hline C18 & 60 & 4.4 & 0.1 & 4.5 & 5 & 0.617 & 0.381 \\
\hline C19 & 60 & 4.4 & 0.1 & 4 & 5 & 0.615 & 0.379 \\
\hline C20 & 60 & 4.5 & 0.1 & 5 & 5 & 0.671 & 0.450 \\
\hline C21 & 60 & 4.4 & 0.1 & 5 & 5 & 0.714 & 0.510 \\
\hline C22 & 60 & 4.2 & 0.1 & 4 & 5 & 0.777 & 0.604 \\
\hline C23 & 60 & 4.3 & 0.1 & 4 & 4 & 0.647 & 0.419 \\
\hline C24 & 60 & 4.3 & 0.1 & 4 & 4 & 0.672 & 0.452 \\
\hline C25 & 60 & 4.2 & 0.1 & 4 & 4 & 0.743 & 0.552 \\
\hline C26 & 60 & 4.4 & 0.1 & 5 & 5 & 0.754 & 0.569 \\
\hline C27 & 60 & 4.5 & 0.1 & 5 & 5 & 0.717 & 0.514 \\
\hline C28 & 60 & 4.4 & 0.1 & 5 & 5 & 0.714 & 0.510 \\
\hline C29 & 60 & 4.4 & 0.1 & 5 & 5 & 0.799 & 0.638 \\
\hline C30 & 60 & 4.5 & 0.1 & 5 & 5 & 0.647 & 0.418 \\
\hline C31 & 60 & 4.4 & 0.1 & 5 & 5 & 0.732 & 0.536 \\
\hline C32 & 60 & 4.3 & 0.1 & 4 & 5 & 0.750 & 0.563 \\
\hline C33 & 60 & 4.2 & 0.1 & 4 & 4 & 0.721 & 0.519 \\
\hline C34 & 60 & 4.2 & 0.1 & 4 & 4 & 0.658 & 0.433 \\
\hline C35 & 60 & 4.2 & 0.1 & 4 & 5 & 0.792 & 0.627 \\
\hline C36 & 60 & 4.1 & 0.1 & 4 & 5 & 0.827 & 0.684 \\
\hline C37 & 60 & 4.5 & 0.1 & 5 & 5 & 0.671 & 0.451 \\
\hline C38 & 60 & 4.5 & 0.1 & 5 & 5 & 0.695 & 0.483 \\
\hline
\end{tabular}


TABLE III. SKEWNESS AND KURTOSIS

\begin{tabular}{|c|c|c|c|c|c|c|c|}
\hline CSF \# & $\mathbf{N}$ & Min & $\operatorname{Max}$ & Skewness & $\begin{array}{l}\text { Std. Error of } \\
\text { Skewness }\end{array}$ & Kurtosis & $\begin{array}{l}\text { Std. Error of } \\
\text { Kurtosis }\end{array}$ \\
\hline $\mathrm{C} 1$ & 60 & 3 & 5 & -1.858 & 0.304 & 2.705 & 0.599 \\
\hline $\mathrm{C} 2$ & 60 & 3 & 5 & -1.007 & 0.304 & -0.138 & 0.599 \\
\hline $\mathrm{C} 3$ & 60 & 3 & 5 & -0.482 & 0.304 & -1.132 & 0.599 \\
\hline $\mathrm{C} 4$ & 60 & 3 & 5 & -0.538 & 0.304 & -1.198 & 0.599 \\
\hline $\mathrm{C} 5$ & 60 & 3 & 5 & -0.274 & 0.304 & -0.972 & 0.599 \\
\hline C6 & 60 & 3 & 5 & -0.665 & 0.304 & -0.813 & 0.599 \\
\hline $\mathrm{C} 7$ & 60 & 3 & 5 & -0.531 & 0.304 & -0.874 & 0.599 \\
\hline $\mathrm{C} 8$ & 60 & 3 & 5 & -0.574 & 0.304 & -0.861 & 0.599 \\
\hline C9 & 60 & 3 & 5 & -0.365 & 0.304 & -0.857 & 0.599 \\
\hline $\mathrm{C} 10$ & 60 & 3 & 5 & -1.312 & 0.304 & 0.796 & 0.599 \\
\hline C11 & 60 & 3 & 5 & -0.909 & 0.304 & -0.171 & 0.599 \\
\hline $\mathrm{C} 12$ & 60 & 3 & 5 & -0.879 & 0.304 & -0.259 & 0.599 \\
\hline $\mathrm{C} 13$ & 60 & 3 & 5 & -1.058 & 0.304 & -0.147 & 0.599 \\
\hline C14 & 60 & 3 & 5 & -0.942 & 0.304 & -0.335 & 0.599 \\
\hline $\mathrm{C} 15$ & 60 & 3 & 5 & -0.333 & 0.304 & -0.637 & 0.599 \\
\hline C16 & 60 & 3 & 5 & -0.669 & 0.304 & -0.471 & 0.599 \\
\hline C17 & 60 & 3 & 5 & -0.604 & 0.304 & -0.548 & 0.599 \\
\hline C18 & 60 & 3 & 5 & -0.611 & 0.304 & -0.524 & 0.599 \\
\hline C19 & 60 & 3 & 5 & -0.555 & 0.304 & -0.566 & 0.599 \\
\hline $\mathrm{C} 20$ & 60 & 3 & 5 & -0.89 & 0.304 & -0.322 & 0.599 \\
\hline $\mathrm{C} 21$ & 60 & 3 & 5 & -0.823 & 0.304 & -0.581 & 0.599 \\
\hline $\mathrm{C} 22$ & 60 & 3 & 5 & -0.421 & 0.304 & -1.214 & 0.599 \\
\hline $\mathrm{C} 23$ & 60 & 3 & 5 & -0.425 & 0.304 & -0.662 & 0.599 \\
\hline $\mathrm{C} 24$ & 60 & 3 & 5 & -0.488 & 0.304 & -0.723 & 0.599 \\
\hline $\mathrm{C} 25$ & 60 & 3 & 5 & -0.242 & 0.304 & -1.131 & 0.599 \\
\hline $\mathrm{C} 26$ & 60 & 3 & 5 & -0.786 & 0.304 & -0.795 & 0.599 \\
\hline $\mathrm{C} 27$ & 60 & 3 & 5 & -0.928 & 0.304 & -0.447 & 0.599 \\
\hline $\mathrm{C} 28$ & 60 & 3 & 5 & -0.823 & 0.304 & -0.581 & 0.599 \\
\hline $\mathrm{C} 29$ & 60 & 3 & 5 & -0.869 & 0.304 & -0.862 & 0.599 \\
\hline C30 & 60 & 3 & 5 & -0.94 & 0.304 & -0.165 & 0.599 \\
\hline C31 & 60 & 3 & 5 & -0.758 & 0.304 & -0.736 & 0.599 \\
\hline C32 & 60 & 3 & 5 & -0.502 & 0.304 & -1.047 & 0.599 \\
\hline $\mathrm{C} 33$ & 60 & 3 & 5 & -0.31 & 0.304 & -1.001 & 0.599 \\
\hline C34 & 60 & 3 & 5 & -0.18 & 0.304 & -0.660 & 0.599 \\
\hline $\mathrm{C} 35$ & 60 & 3 & 5 & -0.397 & 0.304 & -1.290 & 0.599 \\
\hline $\mathrm{C} 36$ & 60 & 3 & 5 & -0.123 & 0.304 & -1.530 & 0.599 \\
\hline C37 & 60 & 3 & 5 & -1.007 & 0.304 & -0.138 & 0.599 \\
\hline C38 & 60 & 3 & 5 & -1.118 & 0.304 & -0.036 & 0.599 \\
\hline
\end{tabular}

Above results shows that which CSFs are the most critical in ERP Implementation process.

\section{E. Top Critical Success Factors}

Respondents considered that the top management support and commitment was the most important according to the analysis in Organizational category. Organization clearly defined strategic goals is second highest CSF in organizational category. An effective management technique is third highest CSF in organizational category (shown in Fig. 7).

Respondents considered that the Human motivation, support and consideration were the most important according to the analysis in HR category. Qualified skilled staff is second highest CSF in HR category. Proper rewards system is third highest CSF in HR category (shown in Fig. 8).

Respondents considered that the Realistic expectation of top management and enterprise were the most important according to the analysis in project management category.
Clear Project objective, mission, strategies and direction is second highest CSF in project management category. Welldesigned project schedule and plan is third highest CSF in project management category (shown in Fig. 9).

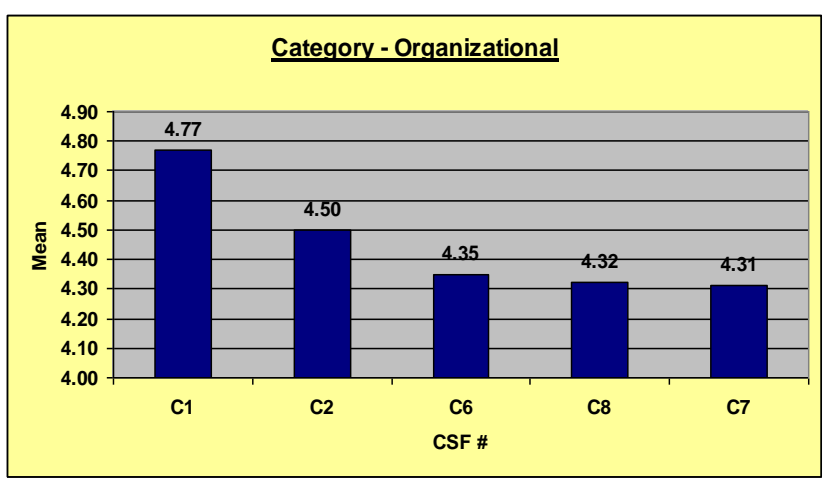

Fig. 7. Top CSFs - category - organizational. 


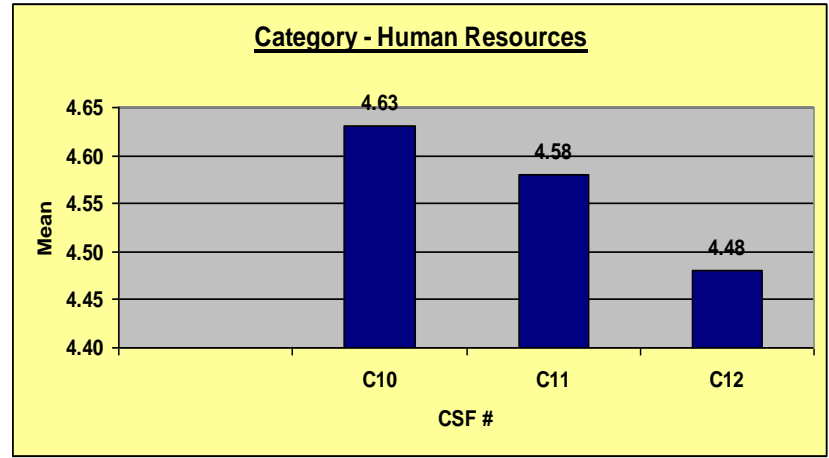

Fig. 8. Top CSFs - category - human resources.

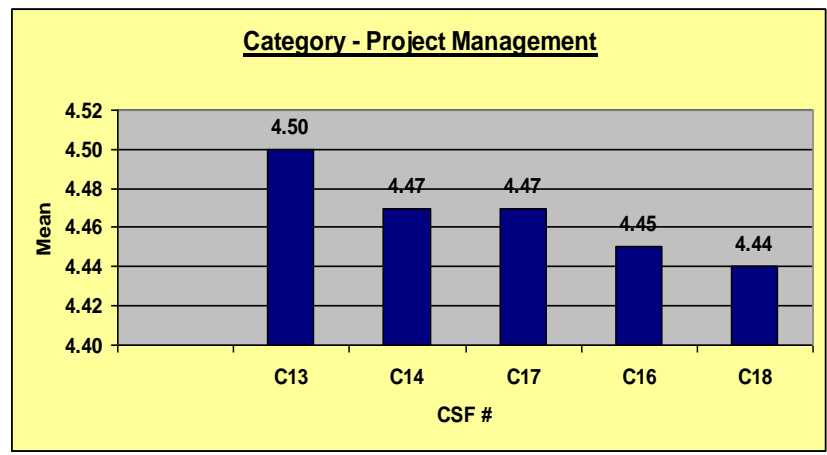

Fig. 9. Top CSFs - category - project management.

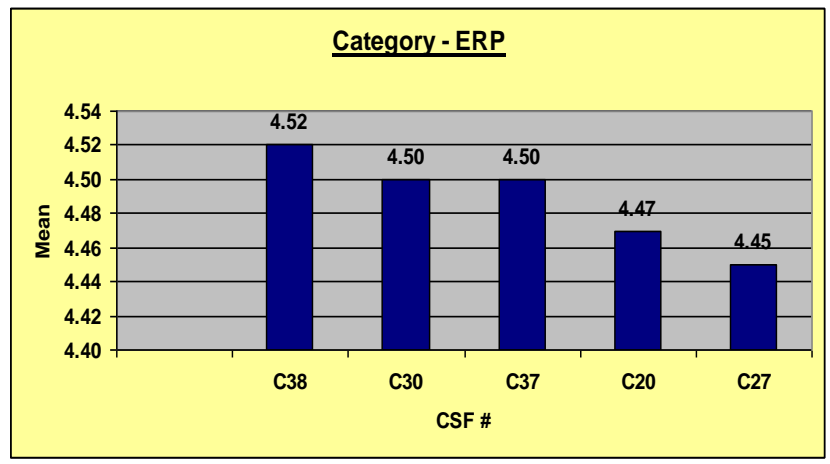

Fig. 10. Top CSFs - category - ERP.

Respondents considered that the End User Training were the most important according to the analysis in ERP category. Reliability of ERP is second highest CSF in ERP category. Proper ERP user documentation is third highest CSF in ERP category (shown in Fig. 10).

\section{CONCLUSION}

This study examines ERP implementation projects using a proposed success factor model. The model was defined based on a thorough review of the literature and feedback from ERP Experts, and the factors were grouped using the own novel categorization for this study. In addition, this research uses its own proposal of synthetic measurement of successful implementation.

The main contribution of this article is one of the first comprehensive studies in the influence of particular factors on the success of ERP projects in Pakistan. This research goes beyond simply stating the subjective opinions of respondents and illustrating the real impact of factors on the success of the ERP project, recognizing those who have the most influence.

This study bridges the gap in the existing literature with an emphasis on the SME sector, as previous research in this area was not focused on the SME sector.

$38 \mathrm{CSF}$ were identified from the existing literature and then grouped into four using factor analysis (Appendix 1). The results of the research clearly indicated that leadership qualities played an important role in obtaining top management support for successful ERP implementation.

ERP consultants and ERP vendors will benefits from the guidelines for successful ERP implementation for Pakistani SMEs. The key results were described in management and non-management factors.

\section{A. Management Factors}

- Top management commitment and organizational support are necessary for successful ERP implementation in Pakistani SMEs.

- End User motivation, support and consideration are also play a vital role for successful ERP implementation in Pakistani SMEs.

- Qualified Staff is another factor for successful ERP implementation in Pakistani SMEs.

- A clear business plan, vision, goals and objectives are essential to guide an ongoing organizational effort to successfully implement ERP.

- The success of ERP implementations depends on user involvement that makes the user comfortable with ERP systems and increases their expertise and knowledge.

- A key factor for the successful implementation of ERP requires a corporate culture that emphasizes the value of sharing common goals in relation to individual activities and the value of trust between partners, employees, Managers and businesses.

\section{B. Non-Management Factors}

- Training and education of End user are an important factor for successful ERP.

- ERP Proper documentation is essential for ERP implementation.

- Good IT infrastructure is required for ERP execution.

- ERP System has a well-defined consistent interface which leads to end user satisfaction.

\section{PRACTICAL IMPLICATIONS}

The results of this study have important practical and research implications. The main conclusions of this study would be of great value for the management of Pakistani SMEs in making decisions about ERP adoption. In addition, it provides information systems researchers and ERP consultants with a better understanding of the adoption of ERP systems in 
the context of developing countries like Pakistan to ensure the successful implementation of the ERP. However, it should be recognized that, since this research emerges from a single, indepth case study, the ability to generalize the findings is limited. The results of the study are expected to be more transferable in the context of Pakistani SMEs in general. In addition, it also provides a benchmark to further enhance the scope of ERP implementation research in Pakistani SMEs among academics and researchers.

\section{RESEARCH LIMITATION}

This study fills the gaps in literature by proposing a model of critical success factors in ERP implementation focusing Pakistani SMEs.

\section{REFERENCES}

[1] Alshubaily, Nisreen F., and Abdullah A. Altameem. "The Role of Strategic Information Systems (SIS) in Supporting and Achieving the Competitive Advantages (CA): An Empirical Study on Saudi Banking Sector." International Journal Of Advanced Computer Science And Applications 8.7 (2017): 128-139.

[2] Abugabah, Ahed, Louis Sanzogni, and Osama Alfarraj. "Evaluating the impact of information systems on end user performance: a proposed model." International Journal of Advanced Computer Science and Applications 1.1 (2010): 22-29.

[3] Moon, Y. (2007). Enterprise Resource Planning (ERP): a review of the literature. International Journal of Management and Enterprise Development, 4(3), 235-238.

[4] Kohlbacher, Markus. "The effects of process orientation: a literature review." Business Process Management Journal 16.1 (2010): 135-152.

[5] Hsu, Pei-Fang, HsiuJu Rebecca Yen, and Jung-Ching Chung. "Assessing ERP post-implementation success at the individual level: Revisiting the role of service quality." Information \& Management 52.8 (2015): 925-942.

[6] Amin, S. U., Yasir Kamal, and Asiya Sohail. "The relationship between transformational leadership and project team performance: Assessing the mediating role of a project team management education." Apeejay Journal of Management Sciences and Technology 3.3 (2016): 1-12.

[7] Ingram, Hadyn, et al. "Internalizing action learning: a company perspective. Establishing critical success factors for action learning courses." International Journal of Contemporary Hospitality Management 12.2 (2000): 107-114.

[8] Ahmad, Ch Saeed, and Saman Malik. "Critical Success Factors for Implementing ERP Systems: Study in Context of SMEs in Pakistan.", Abasyn Journal of Social Sciences - Special Issue: AIC 2016.

[9] Serrano, Nicolas, Josune Hernantes, and Gorka Gallardo. "Serviceoriented architecture and legacy systems." IEEE software 31.5 (2014): 15-19.

[10] Muhleman, Ross, et al. "Cloud Computing: Should I Stay or Should I Cloud?." the Conference on Information Systems Applied Research. 2012.

[11] Solutions, Panorama Consulting. "ERP report: a Panorama Consulting Solutions research report." (2016) .

[12] Solutions, Panorama Consulting. "ERP report: a Panorama Consulting Solutions research report." (2014).

[13] Shatat, Ahmad Saleh. "Critical success factors in enterprise resource planning (ERP) system implementation: An exploratory study in Oman." Electronic Journal of Information Systems Evaluation 18.1 (2015): 55-89.

[14] Apospori, Eleni, Konstantinos G. Zografos, and Solon Magrizos. "SME corporate social responsibility and competitiveness: a literature review." International Journal of Technology Management 58.1/2 (2012): $10-31$.
[15] State of SMEs in Pakistan (accessed on 13-08-2017). (http://www.smeda.org/index.php?option=com_content\&view=article\&id $=7$ : state-of-smes-in-pakistan\&catid=15)

[16] Parida, Vinit, Mats Westerberg, and Johan Frishammar. "Inbound open innovation activities in high - tech SMEs: the impact on innovation performance." Journal of small business management 50.2 (2012): 283309.

[17] Mithas, Sunil, et al. "Information technology and firm profitability: mechanisms and empirical evidence." (2012).

[18] Wong, Ada, et al. "Critical failure factors in ERP implementation." Pacis 2005 Proceedings (2005): 40.

[19] Quigley, Michael, and Maria Burke. "Low-cost Internet of Things digital technology adoption in SMEs." International Journal of Management Practice 6.2 (2013): 153-164.

[20] Ahmed, Irfan, et al. "Information technology and SMEs in Pakistan." International Business Research 3.4 (2010): 237.

[21] Haddara M, Zach O. ERP systems in SMEs: An extended literature review. International Journal of Information Science. 2012;2(6):106-16.

[22] Bharadwaj, Anandhi, et al. "Visions and voices on emerging challenges in digital business strategy." (2013).

[23] Saini, Shashank, Siddhartha Nigam, and Subhas C. Misra. "Identifying success factors for implementation of ERP at Indian SMEs: a comparative study with Indian large organizations and the global trend." Journal of Modelling in Management 8.1 (2013): 103-122.

[24] Marsh, Jacqueline L., et al. "Challenges to sustainable Manufacturing Resource Planning implementation in SMEs: An exploratory study." KES Trans. Sustain. Des. Manuf 1.1 (2014): 291-302.

[25] Saeed, Soobia, et al. "Implementation of Failure Enterprise Systems in Organizational Perspective Framework." International Journal Of Advanced Computer Science And Applications 8.5 (2017): 54-63.

[26] Saxena, Deepak, and Joe McDonagh. "Yet Another 'List' of Critical Success 'Factors' for Enterprise Systems: Review Of Empirical Evidence And Suggested Research Directions." Conference, April 2017.

[27] Li, Hsing-Jung, She-I. Chang, and David C. Yen. "Investigating CSFs for the life cycle of ERP system from the perspective of IT governance." Computer Standards \& Interfaces 50 (2017): 269-279.

[28] Kulkarni, Meera, and Avinash Gyale. "A study of published Literature on ERP: An attempt to find Gaps for further research." International Research Journal of Multidisciplinary Studies 3.6 (2017).

[29] Baykasoğlu, Adil, and İlker Gölcük. "Development of a two-phase structural model for evaluating ERP critical success factors along with a case study." Computers \& Industrial Engineering 106 (2017): 256-274.

[30] Nagpal, Shruti, Ashok Kumar, and Sunil Kumar Khatri. "Modeling interrelationships between CSF in ERP implementations: total ISM and MICMAC approach." International Journal of System Assurance Engineering and Management: 1-17.

[31] Saygili, Ebru E., and Arikan Tarik Saygili. "Contemporary Issues in Enterprise Information Systems: A Critical Review of CSFs in ERP Implementations." Enterprise Information Systems and the Digitalization of Business Functions. IGI Global, 2017. 120-136.

[32] Ali, Mahmood, and Lloyd Miller. "ERP System Implementation in Large Enterprises-A Systematic Literature Review." Journal of Enterprise Information Management 30.4 (2017).

[33] Jagoda, Kalinga, et al. "An integrated framework for ERP system implementation." International Journal of Accounting \& Information Management 25.1 (2017): 91-109.

[34] Baporikar, Neeta. "IT Strategic Planning through CSF Approach in Modern Organizations." Strategic Information Systems and Technologies in Modern Organizations (2017): 1-20.

[35] Mohamed LM. Exploring the Critical Success Factors (CSF) and Limitations of Enterprise Resource Planning (ERP) Systems: The Case of Egyptian Hotels. Journal of Hospitality Management and Tourism. 2015 May 30;6(3):17-29.

[36] Xiong B, Skitmore M, Xia B. A critical review of structural equation modeling applications in construction research. Automation in Construction. 2015 Jan 31;49:59-70. 
APPENDIX 1

List of Critical Success Factors (CSFs):

\begin{tabular}{|l|l|}
\hline CSF \# & Organizational \\
\hline C1 & Top management support and commitment \\
\hline C2 & Organization clearly defined strategic goals \\
\hline C3 & Progressive corporate culture and work climate \\
\hline C4 & Aligned business process \\
\hline C5 & Innovation and competitiveness \\
\hline C6 & Effective management techniques \\
\hline C7 & Good change management and organizational adaptability \\
\hline C8 & Good crisis management and ability to handle surprises \\
\hline C9 & Adequate control system, monitoring and feedback \\
\hline
\end{tabular}

\begin{tabular}{|l|l|}
\hline CSF \# & Human Resources \\
\hline C10 & Human motivation, support and consideration \\
\hline C11 & Qualified skilled staff \\
\hline C12 & Proper rewards system to encourage ideas and innovation \\
\hline
\end{tabular}

\begin{tabular}{|l|l|}
\hline CSF \# & ERP \\
\hline C20 & Clear goals \& objectives (get from ERP) \\
\hline C21 & Controlled ROI on ERP implementation \\
\hline C22 & ERP Benchmarking to identify cutting-edge ERP techniques \\
\hline C23 & Best Consultant selection \\
\hline C24 & Best ERP package selection \\
\hline C25 & $\begin{array}{l}\text { External Consultants involvement in the ERP system } \\
\text { implementation }\end{array}$ \\
\hline C26 & Vendor support \\
\hline C27 & Top Management satisfaction with ERP System \\
\hline C28 & End User satisfaction with ERP System \\
\hline C29 & Relationship of trust among all parties concerned \\
\hline C30 & Reliability of ERP \\
\hline C31 & Well-designed ERP System interface \\
\hline C32 & Aligned between organization culture and ERP system \\
\hline C33 & Aligned between organization structure and ERP system \\
\hline C34 & Good business process reengineering (BPR) \\
\hline C35 & Legacy systems management \\
\hline
\end{tabular}

\begin{tabular}{|l|l|}
\hline CSF \# & Project Management \\
\hline C13 & Realistic expectation of top management and enterprise \\
\hline C14 & Clear Project objective, mission, strategies and direction \\
\hline C15 & ERP Project tasks are reviewed on a periodic basis \\
\hline C16 & Good project communication \\
\hline C17 & Well-designed project schedule and plan \\
\hline C18 & Well defined controlled budget for ERP implementation \\
\hline C19 & Good IT infrastructure \\
\hline
\end{tabular}

